\title{
Stage IVB Thyroid Gland Anaplastic Carcinoma AJCC v8
}

National Cancer Institute

\section{Source}

National Cancer Institute. Stage IVB Thyroid Gland Anaplastic Carcinoma A/CC v8. NCI

Thesaurus. Code C141003.

Stage IVB includes: (T1-T3a, N1, M0); (T 3b, Any N, M0); (T4, Any N, M0). T1: Tumor measuring $2 \mathrm{~cm}$ or less in greatest dimension limited to the thyroid. T2: Tumor measuring more than $2 \mathrm{~cm}$ but $4 \mathrm{~cm}$ or less in greatest dimension limited to the thyroid. T3a: Tumor measuring more than $4 \mathrm{~cm}$ in greatest dimension limited to the thyroid. T3b: Gross extrathyroidal extension invading only strap muscles (sternohyoid, sternothyroid, thyrohyoid, or omohyoid muscles) from a tumor of any size. T4: Tumor of any size with gross extrathyroidal extension. N1: Metastasis to regional nodes. M0: No distant metastasis. (from AJCC 8th Ed.) 